\title{
Ozone Therapy as a treatment modality for temporo-mandibular joint dysfunction
}

\author{
Emad T Daif(1), Hamdy Y Basha(2) \\ (1)Professor of Oral \& Maxillofacial Surgery, Faculty of Oral \& Dental Medicine, Cairo University. Egypt. \\ ${ }^{(2)}$ E.N.T Consultant in the presidential palace, Supervisor of ozone therapy clinic, Al-Haram Hospital. Egypt.
}

\section{ABSTRACT}

\section{OOPEN ACCESS}

\section{Citation}

Daif ET, Basha HY. Ozone Therapy as a treatment modality for temporomandibular joint dysfunction [abstract]. Proceedings of the 5Th WFOT Meeting; 2016 Nov 18-20; Mumbai, India. J Ozone Ther. 2018;2(2). doi: 10.7203/ jo3t.2.2.2018.11132

\section{Academic Editor}

Jose Baeza-Noci, School of Medicine, Valencia University, SPAIN

\section{Editor}

World Federation of Ozone Therapy, Bolgna, ITALY

\section{Received}

December 10, 2017

\section{Accepted}

December 11, 2017

Published

March 4, 2018

\section{Intellectual Property}

Emad T Daif. This is an open access article distributed under the terms of the Creative Commons Attribution License (CC BY 4.0), which permits unrestricted use, distribution, and reproduction in any medium, provided the original author and source are credited.
Temporo-mandibular (TMJ) disorders are of multi-factorial etiology. Numerous attempts have been made to identify the causes however, a great controversy still exists. Emotional stress, malocclusion and bruxism of the teeth are thought to be important factors in TMJ disorders. The limitations of mouth opening, deviation of the mandible on opening, joint noises and pain are among the common signs and symptoms of TMJ disorders. Concerning the treatment, different surgical and non- surgical techniques have been tied by several clinicians. In the recent years, ozone therapy is tried as a new treatment modality for many diseases particularly joint affection. So this study was carried out to assess the clinical outcome of ozone therapy in TMJ disorders. Twenty five patients (16 Females, 9 Males) complaining of TMJ disorders were selected for this study.

Every affected joint received $2 \mathrm{ml}$ of ozone gas in concentration of $10 \mu \mathrm{g} / \mathrm{ml}$ by direct injection of the gas into the joint cavity. The injection was repeated two times per week for tree weeks.

The clinical signs \& symptoms before and after treatment were assessed according to Helkimo's clinical dysfunction index. The results showed that, $84 \%$ of the patients became symptoms free or improved while; only $16 \%$ showed unchanged signs and symptoms after completion of the treatment protocol. 